\title{
Relative Nutritional Deficiencies Associated with Centrally Acting Monoamines [Retraction]
}

Hinz M, Stein A, Uncini T. Int J Gen Med. 2012;5:413-430.

The Editor-in-chief and Publisher of International Journal of General Medicine wish to retract the published article.

Following the conclusion of our investigation the decision has been made to retract the published article. The authors did not provide the required IRB and informed consent information relating to this study and it was determined the study did not meet the standard ethical publication requirements for studies involving human subjects in research. These requirements are based on guidelines issued by the World Medical Association and the International Committee of Medical Journal Editors. Additionally, the authors did not provide the required study protocols, raw data and other study documents relating to this study as requested. Given our concerns about the standard of research ethics, competing interests and that the authors have not supplied the information we requested to verify and validate the reported findings, the editor has determined the article should be retracted.

Our decision-making was informed by our policy on publishing ethics and integrity and the COPE guidelines on retraction.

The retracted article will remain online to maintain the scholarly record, but it will be digitally watermarked on each page as "Retracted".

\section{Publish your work in this journal}

The International Journal of General Medicine is an international, peer-reviewed open-access journal that focuses on general and internal medicine, pathogenesis, epidemiology, diagnosis, monitoring and treatment protocols. The journal is characterized by the rapid reporting of reviews, original research and clinical studies across all disease areas. The manuscript management system is completely online and includes a very quick and fair peer-review system, which is all easy to use. Visit http://www.dovepress.com/ testimonials.php to read real quotes from published authors. 